\title{
Multicomponent aerosol dynamics model UHMA: model development and validation
}

\author{
H. Korhonen, K. E. J. Lehtinen, and M. Kulmala \\ Department of Physical Sciences, University of Helsinki, Helsinki, Finland \\ Received: 18 November 2003 - Published in Atmos. Chem. Phys. Discuss.: 20 January 2004 \\ Revised: 26 April 2004 - Accepted: 18 May 2004 - Published: 18 May 2004
}

\begin{abstract}
A size-segregated aerosol dynamics model UHMA (University of Helsinki Multicomponent Aerosol model) was developed for studies of multicomponent tropospheric aerosol particles. The model includes major aerosol microphysical processes in the atmosphere with a focus on new particle formation and growth; thus it incorporates particle coagulation and multicomponent condensation, applying a revised treatment of condensation flux onto free molecular regime particles and the activation of nanosized clusters by organic vapours (Nano-Köhler theory), as well as recent parameterizations for binary $\mathrm{H}_{2} \mathrm{SO}_{4}-\mathrm{H}_{2} \mathrm{O}$ and ternary $\mathrm{H}_{2} \mathrm{SO}_{4}-\mathrm{NH}_{3}-\mathrm{H}_{2} \mathrm{O}$ homogeneous nucleation and dry deposition. The representation of particle size distribution can be chosen from three sectional methods: the hybrid method, the moving center method, and the retracking method in which moving sections are retracked to a fixed grid after a certain time interval. All these methods can treat particle emissions and atmospheric transport consistently, and are therefore suitable for use in large scale atmospheric models. In a test simulation against an accurate high resolution solution, all the methods showed reasonable treatment of new particle formation with 20 size sections although the hybrid and the retracking methods suffered from artificial widening of the distribution. The moving center approach, on the other hand, showed extra dents in the particle size distribution and failed to predict the onset of detectable particle formation. In a separate test simulation of an observed nucleation event, the model captured the key qualitative behaviour of the system well. Furthermore, its prediction of the organic volume fraction in newly formed particles, suggesting values as high as 0.5 for $3-4 \mathrm{~nm}$ particles and approximately 0.8 for $10 \mathrm{~nm}$ particles, agrees with recent indirect composition measurements.
\end{abstract}

Correspondence to: $\mathrm{H}$. Korhonen

(hannele.s.korhonen@helsinki.fi)

\section{Introduction}

Atmospheric aerosols are typically multicomponent particles with complex chemical composition. Particles in the submicron size range consist mainly of sulphate, nitrate, ammonium, elemental carbon, primary and secondary organic matter, and transition metals (Jimenez et al., 2003; Ball et al., 2003; Lake et al., 2003; Putaud et al., 2002). In the supermicron range, on the other hand, the main constituents are sea salt, nitrate, crustal materials, and primary organic matter (Ball et al., 2003; Seinfeld and Pandis, 1998). The relative contributions of different constituents in the particles are strongly dependent on their production mechanisms and the ambient conditions, and thus vary distinctively from site to site.

The particle composition, as a function of its size, determines the magnitude and sign of its climate forcing. The particles can alter the Earth's radiative balance directly by absorbing and scattering incoming solar radiation, and by absorbing and emitting outgoing thermal radiation. When scattering the incoming short wave radiation dominates, as it does for sulphate and nitrate aerosols (Charlson et al., 1992; Adams et al., 2001), the net effect of the forcing is cooling. Conversely, black carbon particles mainly absorb light and thus end up warming the climate (Jacobson, 2001). For mineral dust aerosols, on the other hand, it is still impossible to quantify, or even to resolve the sign of the net direct forcing (Sokolik et al., 2001). Uncertainties lie in the representative way to describe the dust size distribution and refractive indices (Sokolik and Toon, 1996; Liao and Seinfeld, 1998; Claquin et al., 1998) which together determine the dust optical properties. Similar uncertainties surround the direct forcing effects of organic particles. In addition, the diverse estimates of the global production rate of organic particles (Kanakidou et al., 2000; Chung and Seinfeld, 2002) further complicate the quantification of their climatic effects. Still, the most recent overview of climate research concludes that 
the net direct effect of organic carbon aerosols from fossil fuel and biomass burning is cooling and may even be comparable in magnitude to sulphate aerosol forcing (Intergovernmental Panel on Climate Change, 2001).

In addition to the direct climate forcing, aerosol particles can disturb the radiation balance indirectly through the formation of clouds. The ability of particles to serve as cloud condensation nuclei (CCN) is strongly dependent on their size and water uptake properties. Water-soluble inorganic acids and salts, such as sulphates, nitrates, and sea salt, absorb water readily which makes them substantial contributors to cloud droplet formation (Jones et al., 1994; Murphy et al., 1998; Feingold et al., 1999; Ghan et al., 2001a; Ishizaka and Adhikari, 2003). On the other hand, the estimate of $\mathrm{CCN}$ forming potential of organic aerosols, which contain numerous compounds with widely varying responses to water, is highly uncertain. Recent laboratory and field studies suggest, however, that at least under some conditions organic particles can lead to significant $\mathrm{CCN}$ formation (Matsumoto et al., 1997; Giebl et al., 2002; Ishizaka and Adhikari, 2003). Furthermore, large mineral dust particles coated with sulphate (Levin et al., 1996) can be effective initiators of cloud formation; the lack of sufficient data makes, however, accurate quantification of their indirect climate forcing presently impossible (Intergovernmental Panel on Climate Change, 2001).

The knowledge of the size distribution and composition of atmospheric aerosols is essential also to determine their effects on public health. Epidemiological studies have revealed that e.g. mortality, respiratory and cardiovascular hospital admissions, and the use of asthma medication show correlation with atmospheric particulate load (Dockery et al., 1993; Künzli et al., 2000; Atkinson et al., 1999; Gordian and Choudhury, 2003). Although the air quality standards are based on ambient particulate mass, traditionally measured for particles smaller than $10 \mu \mathrm{m}\left(\mathrm{PM}_{10}\right)$ and smaller than $2.5 \mu \mathrm{m}\left(\mathrm{PM}_{2.5}\right)$ in size, several studies have stressed the importance of ultrafine particle concentration (Seaton et al., 1995) or particle surface area (Brown et al., 2001; Maynard and Maynard, 2002). Furthermore, the chemical composition of the particles affects their toxicity and candidates for the biologically active constituents are plenty. Studies have linked organic (Hiura et al., 1999; Boland et al., 2000), metallic (Goldsmith et al., 1998; Lambert et al., 2000), and acidic (Wyzga and Folinsbee, 1995) components with the particle health effects. A recent study by Obot et al. (2002) suggests that the overall surface composition of the particles, rather than any one component, may be the important factor, offering an explanation to the fact that particles from many distinct sources are biologically active.

The need to investigate the factors shaping the size distribution and composition of atmospheric particles calls for effective and reliable aerosol dynamics models. Such multicomponent models, differing greatly in their accuracy to describe the particle distribution properties and dynamics, have been applied to address e.g. air quality (Ackerman et al., 1998; Meng et al., 1998), particle dynamics in marine boundary layer (Fitzgerald et al., 1998), and aerosol formation (Pilinis et al., 1987; Pirjola et al., 2003). The latter has been a focus of intensive research at the University of Helsinki where continuous observations of nucleation events (Mäkelä et al., 1997, 2000) and theoretical work addressing new particle formation (e.g. Laaksonen and Oxtoby, 1995; Korhonen et al., 1999; Napari and Laaksonen, 2000; Vehkamäki and Ford, 2000) have been linked with the help of multicomponent microphysical models AEROFOR2 (Pirjola and Kulmala, 2000a) and MONO32 (Pirjola and Kulmala, 2000b; Pirjola et al., 2003), applying sectional and multimodal monodisperse particle descriptions, respectively. While these models have succeeded in reproducing the qualitative features of observed phenomena, recent improvements in understanding the inital steps of particle formation and growth as well as advancements in the numerical description of particle size distribution necessitate updating of modelling tools.

This paper describes the development of a sizesegregated multicomponent aerosol code UHMA (University of Helsinki Multicomponent Aerosol model), which provides a computationally efficient tool for detailed studies of tropospheric aerosol particles. With the focus on the aerosol dynamic processes that enhance or hinder new particle formation and growth to climatically active sizes, the first model version incorporates novel parameterizations for binary sulphuric acid-water nuclation, ternary sulphuric acidammonia-water nucleation, and the calculation of particle water and ammonia contents, as well as a recently revised formulation of condensation flux onto the free molecular regime particles. In addition to nucleation and multicomponent condensation, the model includes particle coagulation and a recent semiempirical parameterization for particle dry deposition. Although not discussed in this study, the model is also capable of simulating primary particle emissions from natural or anthropogenic sources, detrainment and entrainment as well as heterogenous nucleation on insoluble particles.

The following section presents the treatment of aerosol microphysical processes and the description of the particles in the model. Section 3 discusses the model performance in two separate nucleation event simulations: The first simulation compares the size distribution description approaches incorporated into UHMA against a high resolution solution, and the second test demonstrates the potential of the model to simulate real atmospheric nucleation events. Finally, Sect. 4 summarizes the findings of the study. 


\section{Model description}

\subsection{Particle composition}

In the size-segregated distribution description applied in UHMA, the discretizing of the particles over the size coordinate bases on the volume of the particle core. The core components in the first model version can be sulphuric acid, water-soluble organic compounds, and an arbitrary number of insoluble constituents representing e.g. mineral dust, water-insoluble organics, and black carbon. The particle water and ammonia content, on the other hand, does not contribute to the core volume but is determined at every time step by equilibration of gaseous water and ammonia with the particulate sulphate and water-soluble organic fraction. The model calculates the density, and thus the volume, of the sulphate-water-ammonia portion of the particles exactly (Napari et al., 2002a); the rest of the liquid phase components form an ideal solution.

The size distribution description conserves the characteristic dynamic variables, i.e. number concentration and partial volume concentrations of different constituents, at every time step. The particle composition may vary from one size section to another; yet, at a given time step all the particles in a given section are uniform in composition. This assumption of internally mixed particles in a section somewhat limits the accuracy of e.g. CCN formation predictions because, in reality, the water uptake properties of same sized particles with different chemical composition may deviate markedly. The gain attained in accuracy by allowing several types of same sized particles would, however, be lost in increasing the computational burden manyfold.

Incorporation of organic compounds into the model is essential because, depending on the location, organic matter can be responsible for close to or even more than $50 \%$ of the fine aerosol mass (Zappoli et al., 1999; O'Dowd et al., 2000). Despite this weighty fraction, most of the organic compounds in the fine aerosol remain unidentified. On the other hand, given the vast number of organic species found in the particles, a detailed representation of organic matter in an aerosol dynamics model would be cumbersome, if not impossible. Lumping compounds with similar properties together offers a flexible way to reduce the number of simulated species, and yet to attain a reasonable description of the aerosol organic content. Several studies have shown that the modelling results using this approach are in good agreement with observations (Meng et al., 1998; Chung and Seinfeld, 2002; Koo et al., 2003). In UHMA, the number or the properties of lumped organic compounds are not predetermined. Instead, it is possible to tailor them at the beginning of the simulation to best represent the conditions investigated.

\subsection{Aerosol microphysics}

\subsubsection{Condensation/evaporation}

Condensation of low volatile gas phase species shapes the particle chemical composition and size distribution, and provides an important mechanism by which small particles grow to become climatically active. In UHMA, vapours contributing to particle growth are sulphuric acid, ammonia, water and an unspecified number of water-soluble and water-insoluble organic compounds. Water and ammonia content of the particles is calculated based on an equilibrium assumption whereas the condensation of sulphuric acid and the organic compounds is treated dynamically.

The condensation flux of atmospheric vapours onto the particles depends on the properties of the vapour, the particle composition, and the shape of the particle distribution. The conventional formulation of the flux assumes that the diffusion coefficient of the particles is much smaller than that of the vapour and can therefore be neglected. Following similar reasoning, the diameter of the vapour molecule is often neglected in the calculation of the flux. As Lehtinen and Kulmala (2003) have pointed out, these assumptions do not hold true for particles in the nucleation mode but underestimate the condensation flux onto these particles. We have therefore implemented a revised flux formulation suggested by Lehtinen and Kulmala (2003) which accounts for the moleculelike properties of the small particles.

The correction for the noncontinuum effects of the flux in the submicron particle range follows the Fuchs-Sutugin formulation (Fuchs and Sutugin, 1971), which also takes into account the possibility that all vapour molecules that encounter the particle surface do not stick to the particle. While some experimental studies suggest that the sticking probability, or mass accomodation coefficient, is well below one for many condensable inorganic and organic compounds (Pöschl et al., 1998; Van Dingenen and Raes, 1991; Worsnop et al., 2001; Guimbaud et al., 2002), others report sulphuric acid and ammonia sticking probability close to unity (Weber et al., 1995; Hanson and Kosciuch, 2003). Further support comes from theoretical studies by Clement et al. (1996) and by Morita (2003): the former claims that the coefficient is close to unity for all the condensable atmospheric vapours, whereas the latter argues on the basis of molecular dynamics simulations that the coefficient is close to one for methanol on methanol/water surfaces. In the model, the mass accomodation coefficient can be chosen for sulphuric acid and for the organic compounds individually; however, we take 1 as the default input value. The diffusion coefficient of the vapour molecules is calculated according to Reid et al. (1987).

Very little direct data exists on the chemical composition of nucleation mode particles, mainly because the aerosol mass in this size range is too small for reliable analysis with the current instrumentation. Although it is widely recognized that the most likely nucleating species in the atmosphere 
are inorganic, measurements have revealed that ambient sulphuric acid concentrations are typically insufficient to explain the observed growth rates of nanosized particles (Boy et al., 2003). Furthermore, indirect experimental evidence indicates that the dominant contributors to nucleation mode chemical composition, at least in forested regions, are organic compounds (O'Dowd et al., 2002). In UHMA, the onset of low or semivolatile organic vapour condensation onto the nanosized inorganic clusters is determined by NanoKöhler theory (Kulmala et al., 2004a), which describes the thermodynamic equilibrium between an inorganic cluster, water, and a water soluble organic compound. For the organic vapour, the theory predicts the saturation vapour pressure above the cluster surface, dependent on the vapour properties as well as the cluster composition and curvature. With the help of this information, the cluster size at which the organic compound initiates spontaneous cluster growth can be determined. For further details of the thermodynamic model, we refer the reader to Kulmala et al. (2004a). The calculation of sulphuric acid condensation assumes negligible saturation vapour pressure above particle surface.

Instead of carrying information on the water and ammonia content of the particles along, the model equilibrates the particulate sulphate and water soluble organic content with gaseous water and ammonia at every time step. The assumption of homogeneous chemical composition of the particles within a size section does not allow for the possibility of surface active organic compounds that could influence the transport of water to the inorganic portion of the particles. Instead, we have determined the total water content of the particles containing organic and inorganic material applying the widely used Zdanovskii, Stokes, and Robinson (ZSR) model (Stokes and Robinson, 1966). This approach assumes that the water content of the mixed composition particle is equal to the sum of the liquid water contents of the individual pure components at the same relative humidity. Several laboratory studies have found the ZSR model adequate for a firstorder estimation of the hygroscopic growth factors of mixed organic-inorganic aerosol particles (Cruz and Pandis, 2000; Choi and Chan, 2002).

Unfortunately, the understanding of the hygroscopicity of ambient aerosol organic mixtures is deficient. Cruz and Pandis (2000) measured no growth for pure pinonic acid particles at RH below $95 \%$ and a growth factor of $1.1 \pm 0.1$ for pure glutaric acid particles at RH greater than $85 \%$. Similarily, Virkkula et al. (1999) found a growth factor close to 1.1 at $\mathrm{RH}=84 \%$ for organic particles formed from oxidation products of monoterpenes. Although these measurements cover only a fraction of the aerosol organic compounds, they are in good agreement with the "less-hygroscopic" particles frequently observed in field measurements (Svenningson et al., 1992; Zhang et al., 1993). We approximate therefore the growth factor of the modelled water soluble organic compound to be 1.1 for $100 \mathrm{~nm}$ particles at $\mathrm{RH}=90 \%$, values drawn from hygroscopicity measurement data at Hyytiälä forest site in southern Finland (personal communication with T. Petäjä, 2003). The calculation of the particle sulphate content equilibrium with gas phase species follows novel parameterizations by Napari et al. (in preparation, 2004) and is in the binary $\mathrm{H}_{2} \mathrm{SO}_{4}-\mathrm{H}_{2} \mathrm{O}$ case based on thermodynamic model of Zeleznik (1991), and in ternary $\mathrm{H}_{2} \mathrm{SO}_{4}-\mathrm{NH}_{3}-\mathrm{H}_{2} \mathrm{O}$ case on thermodynamic model of Clegg et al. (1998) (available at http://www.hpc1.uea.ac.uk/ e770/aim.html).

\subsubsection{Nucleation}

Homogeneous nucleation is a significant source of aerosol number concentration (Kulmala, 2003; Kulmala et al., 2004b). Unfortunately, several uncertainties surround the atmospheric microphysical nucleation mechanism. Many studies have suggested the binary nucleation of sulphuric acid and water to be the prevailing mechanism (Doyle, 1961; Raes and Van Dingenen, 1992; Kulmala et al., 1998), and in some cases this theory has succesfully explained the observed formation rates of new particles (Weber et al., 1999; Pirjola et al., 1998). Field studies have shown, however, that measured nucleation rates frequently exceed those predicted by sulphuric acid-water nucleation theories and laboratory measurements (Covert et al., 1992; Clarke et al., 1998; Birmili et al., 2000; Viisanen et al., 1997). A possible explanation to this discrepancy is the participation of a third compound to the nucleation process, the most likely species being ammonia $\left(\mathrm{NH}_{3}\right)$. Apart from being abundant in the atmosphere, ammonia has the ability to lower the vapour pressure of sulphuric acid above solution surfaces (Marti et al., 1997), thus enhancing the expected nucleation rates by several orders of magnitude compared to $\mathrm{H}_{2} \mathrm{SO}_{4}-\mathrm{H}_{2} \mathrm{O}$ nucleation alone. This has also been demonstrated by recent theoretical calculations (Coffman and Hegg, 1995; Napari et al., 2002a) and preliminary experimental findings (Ball et al., 1999). It seems therefore probable that binary nucleation can be viable only when the ammonia concentration is negligible and the sulphuric acid concentration sufficiently high, e.g. in the upper troposphere or in industrial plumes.

Furthermore, one cannot rule out other potential new particle formation mechanisms. Some studies have suggested that compounds capable of nucleating homogeneously could form via oxidation of biogenic and anthropogenic organic vapours (Bonn and Moortgat, 2002). Chemical identification of these low volatile oxidation product compounds responsible for new particle formation has not, however, been successful. In addition, compared to corresponding neutral clusters, charged clusters formed on ions are more stable and can grow faster, thus supporting the ion mediated nucleation mechanism (Yu and Turco, 2000). Preliminary experimental results indicate, however, that at least in some locations the ion formation rate is too slow to explain the observed nucleation rates.

Despite no final certainty on the nucleation mechanism exists, strong theoretical and experimental evidence points out 
the key role of sulphuric acid in particle formation. Thus, the model incorporates new particle formation schemes of binary $\mathrm{H}_{2} \mathrm{SO}_{4}-\mathrm{H}_{2} \mathrm{O}$ and ternary $\mathrm{H}_{2} \mathrm{SO}_{4}-\mathrm{H}_{2} \mathrm{O}-\mathrm{NH}_{3}$ nucleation, and chooses the correct scheme on the basis of ammonia mixing ratio, the critical value being $0.1 \mathrm{ppt}$ due to the lower validity limit of the ternary parameterization. Since the ternary nucleation rates corresponding to ammonia concentrations below this critical value are very small, this assumption does not introduce errors in the model simulations. As earlier explained, the model does not carry information on the water and ammonia content of the particles. The nucleated particles are therefore partitioned to the existing size grid based on the number of sulphuric acid molecules they contain. If this core size of the formed particles is smaller than the lower limit of the smallest size bin, the total volume concentration of sulphuric acid is conserved and the number concentration in the smallest section adjusted accordingly.

The formation rate of critical clusters, along with their size and number of constituent molecules, arises as an output from recently revised binary (Vehkamäki et al., 2002) and ternary nucleation (Napari et al., 2002b) parameterizations. These parameterizations build on a thermodynamically consistent version of classical nucleation model, and follow rigorous nucleation kinetics and an improved hydrate model (Noppel et al., 2002). Noppel et al. (2002) have demonstrated that the nucleation rates from the model behind the binary parameterization generally fall within experimental area although some disagreement appears at low temperatures. Similarily, the ternary parameterization reproduces the qualitative features of experimental data well (Kim et al., 1998; Ball et al., 1999).

\subsubsection{Coagulation}

In addition to being a significant sink of aerosol number, coagulation may be an important mechanism for the growth of freshly nucleated particles. Furthermore, coagulation is essential for determining the number concentration of newly formed particles that surpass the observational detection limit, as well as the fraction of particles that reach climatically active sizes.

The coagulation kernel used here accounts only for Brownian diffusion which for submicron particles dominates over other kernels. For small particles, the correction for noncontinuum effects in the kernel bases on the work of Fuchs (1964). The collision efficiency of the particles is dependent on their total size; yet, UHMA discretizes the particles over the size coordinate based on their core size. The model determines the water and ammonia content of the particles through equilibration considerations and thus instead of being fixed, the total volume of the particles in each bin is dependent on the particle core composition as well as the ambient relative humidity and ammonia mixing ratio. The coagulation kernel needs therefore to be recalculated at every time step.
The particles formed in the collisions are retracked into the existing size sections based on their core volume. If the core size of the particle formed in the collision falls beyond the simulated size range, the total volume concentration of each of its core component is conserved while the number concentration in the largest section rises accordingly.

\subsubsection{Dry deposition}

Particle dry deposition removes most efficiently particles smaller than $50 \mathrm{~nm}$ and larger than few micrometers in size; the former via Brownian diffusion and the latter via inertial impaction and gravitational settling. Both of these mechanisms cease to be effective for accumulation mode particles and the deposition velocity shows therefore a minimum for particles in this size range.

In this study, we have examined particle formation in forested regions. The calculation of size dependent particle dry deposition velocities above the forest canopy bases on a semiempirical deposition model by Rannik et al. (2003), which makes use of eddy covariance measurements of particle number fluxes and particle size distribution measurements conducted at Hyytiälä forest station (southern Finland). The flux measurements at this site detect only particles of $10-500 \mathrm{~nm}$ in diameter. To account for the deposition loss of newly formed particles, we extrapolated the model to particles below $10 \mathrm{~nm}$. This was done by applying the size dependent formulation of the particle deposition velocity suggested by Rannik et al. (2003) and taking advantage of empirical parameters, which determine the level of collection curve, the diameter of minimum collection efficiency, and the steepness of increase in collection efficiency after the minimum, derived from the measurements of $10-500 \mathrm{~nm}$ particles.

\subsection{Size distribution description}

One motivation behind the development of UHMA has been to build a model that can, after e.g. the inclusion of sea salt and nitrates into the particle content, simulate aerosol dynamics reliably in a large scale model. In such a model, minimizing the computational burden of the aerosol module is essential. At the same time, the particle size distribution description should capture the distribution evolution accurately, and be able to allocate the particles from emission, nucleation and transport processes consistently. In this context, the most customary approaches to describe the particle size distribution have been modal (Ackerman et al., 1998; Wilson et al., 2001; Ghan et al., 2001b) or sectional (Adams and Seinfeld, 2002; Griffin et al., 2002; Gong et al., 2003). The former represents the continuous size distribution as the superposition of several lognormal modes; the latter approximates the distribution by a finite number of size sections whose locations can be let to vary or can be fixed upon particle growth. Of these approaches, the most advantageous 
in treating particle transport, emissions and homogeneous nucleation is the fixed sectional method. Recent modifications to this method, such as the hybrid structure (Jacobson and Turco, 1995), the moving center structure (Jacobson, 1997), Bott's method (Dhaniyala and Wexler, 1996), the partioned flux integrated semi-Lagrangian method (Nguyen and Dabdub, 2002), and retracking moving sections to a fixed grid, have tackled the problems related to numerical diffusion upon condensation and thus made it an even more viable candidate for models which require computational efficiency, i.e. small number of size sections.

In UHMA, it is possible to choose the way to describe the particle size distribution from three sectional methods, all potential for use in large scale atmospheric models. Each of the methods have several advantages in simulating the size distribution dynamics; yet, all of them suffer from shortcomings that restrict their accuracy under some atmospheric conditions. Although it is not yet known which of them is the most suited for 3-D simulations, by completing each other they allow a computationally viable application of UHMA to a wide range of atmospheric problems. In Sect. 3, we demonstrate and compare the performance of the methods in a new particle formation simulation.

Firstly, dividing the particle material to core and non-core volumes, as explained above, and keeping the size sections, based on the core volume, fixed in location throughout the simulation results in what Jacobson and Turco (1995) called a hybrid structure. This structure eliminates the numerical diffusion, inherent to fixed grid methods, associated with the condensation of water and ammonia; if the particles gain or lose core material, however, they must be fitted back to the fixed grid, i.e. splitted between two adjacent size sections.

When the moving center approach (Jacobson, 1997) is applied to the particle core material, the section boundaries are fixed but particle core size can vary within the section. As soon as the core size reaches the upper or lower limit of the section, all the particles jump to the adjacent section. Because the method does not partition the particles between the sections, this step eliminates the artificial spreading of the distribution. Averaging of the moved particles with the preexisting ones in the section causes, however, some numerical diffusion. On the whole, the method prevents most of artificial diffusion, and permits a fairly realistic treatment of particle emissions, nucleation, and transport.

The third size distribution method is a modified moving sectional approach in which, after a certain number of time steps, the sections are retracked to a fixed grid based on the core volume (e.g. Lurmann et al, 1997). Between the retrackings, the particle cores are allowed to grow to their exact sizes thus eliminating artificial widening of the size distribution. The approach has, however, a drawback in simulating new particle formation: Continuous nucleation causes problems if the first formed particles grow due to condensation and self-coagulation and leave no size bin small enough to put freshly nucleated particles into. Placing these particles into the smallest section with the pre-existing ones and requiring conservation of number and mass, the moving method somewhat underestimates the growth of earlier nucleated particles. Another option, creating a new size section for the nucleating particles, increases the computational burden of the code.

\section{Model validation}

\subsection{Performance of size distribution representations}

Of the studies investigating how the numerical representation of the particle size distribution in the model affects the simulation results, only a few have discussed new particle formation and growth (Pirjola et al., 1999; Jacobson, 2002; Korhonen et al., 2003). Accurate simulation of these small particles is, however, of great importance in order to predict the number concentration of detectable or climatically active particles. This in mind, we tested the performance of the three size distribution approaches incorporated into the model in a simulation of a new particle formation event. Optimizing the treatment of nucleated particles in the retracking method required two simulations: In the first one, no additional size sections were created for the newly formed particles. In the second simulation, a new size section for the smallest particles appeared, if necessary, after every ten-minute simulation period. As the retracking to a fixed grid was done once an hour, the number of sections in excess to the fixed grid was six at the most. Creating new sections more often would have improved the model performance but we wished to retain the difference in computational times required by the methods within $30 \%$.

In the 10-h test simulation, the particle distribution was shaped by nucleation, multicomponent condensation/evaporation, coagulation, and dry deposition. Because the test focused on new particle formation and growth, only one low volatile organic compound, with a saturation vapour concentration $10^{6} \mathrm{~cm}^{-3}$, described the organic fraction of the particles. A more realistic assumption of additional higher volatile organic vapours, which could condense onto larger pre-existing particles only, would not change the conclusions of the test. For simplicity, both sulphuric acid and the organic vapour followed a semisinusoidal pattern peaking $2 \mathrm{~h}$ after the beginning of the simulation at $4 \cdot 10^{6} \mathrm{~cm}^{-3}$ and $10^{7} \mathrm{~cm}^{-3}$, respectively, while the ammonia mixing ratio had a constant value of $4 \mathrm{ppt}$.

For all of methods, the simulated particle core size range from $0.7 \mathrm{~nm}$ to $2 \mu \mathrm{m}$ was split into 20 logarithmically spaced size sections. As a reference, we used results obtained from a hybrid model with 200 size sections, a level of resolution that reproduces the results of a discrete solution with very good accuracy (Korhonen et al., 2003). The pre-existing particle population, roughly corresponding to a typical particle distribution in boreal forests prior to a new particle formation event (Mäkelä et al., 2000), consisted of two lognormal 


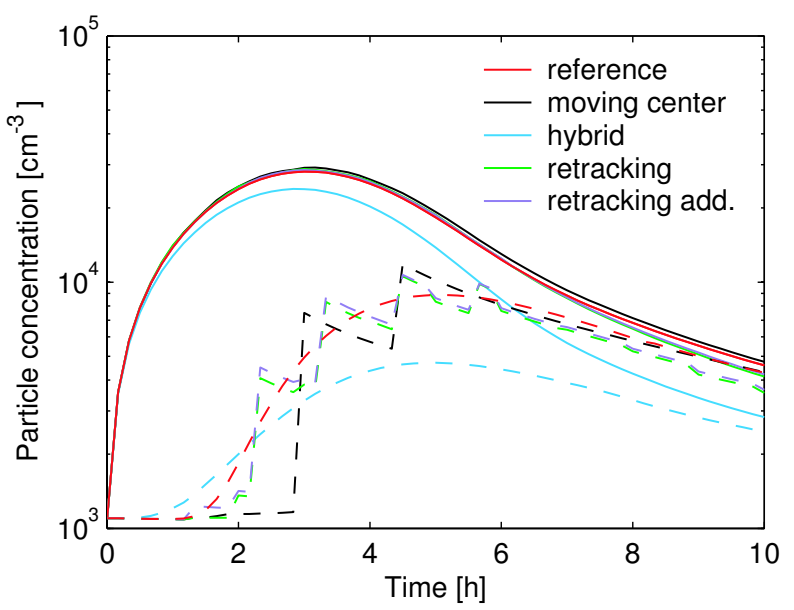

Fig. 1. Total particle concentration (solid lines) and the concentration of larger than $3 \mathrm{~nm}$ particles (dashed lines) as predicted by different size distribution descriptions in the first test case. The purple line, labeled "retracking add", refers to the retracking method in which new size section was created for nucleated particles after every ten minutes.

modes: one in Aitken mode $\left(\mathrm{N}=1000 \mathrm{~cm}^{-3}, \overline{\mathrm{D}}_{p, d r y}=50 \mathrm{~nm}\right.$, and $\sigma=1.25)$ and the other in accumulation mode region $\left(\mathrm{N}=100 \mathrm{~cm}^{-3}, \overline{\mathrm{D}}_{p, d r y}=140 \mathrm{~nm}\right.$, and $\left.\sigma=1.3\right)$. In these preexisting particles, the initial dry volume ratio of sulphuric acid and the organic compound was 1:1. Although only one set of initial conditions is presented here, the conclusions of the comparison of the methods are valid for new particle formation simulations in general.

Figure 1 demonstrates that with the tested resolution the approaches predict the total particle number concentration with good accuracy, apart from the hybrid structure. In this structure, numerical diffusion widens the nucleation mode leading to an overestimation of the intramodal coagulation rate of the smallest particles. Although not plotted here, a comparison of total surface area and volume concentrations predicted by the three methods gives results very similar to Fig. 1. The figure reveals also the built-in problems with moving center and retracking methods to predict the formation rate of detectable $3 \mathrm{~nm}$ particles. Both approaches place the newly formed particles into a section with pre-existing ones, and then average to conserve number and volume concentrations. Doing this delays artificially the growth of earlier formed particles and leads to burst-like, rather than continuous, formation of detectable particles. Retracking the moving sections to a fixed grid after every hour corrects for the delay slightly and the retracking approach predicts new particles in observable size range almost an hour before the moving center method. The two simulations with the retracking method, on the other hand, predict surprisingly similar behaviour of the detectable particle concentration.

Figure 2 shows the particle size distribution at the midpoint and at the end of the simulation. After $5 \mathrm{~h}$, the retrack-
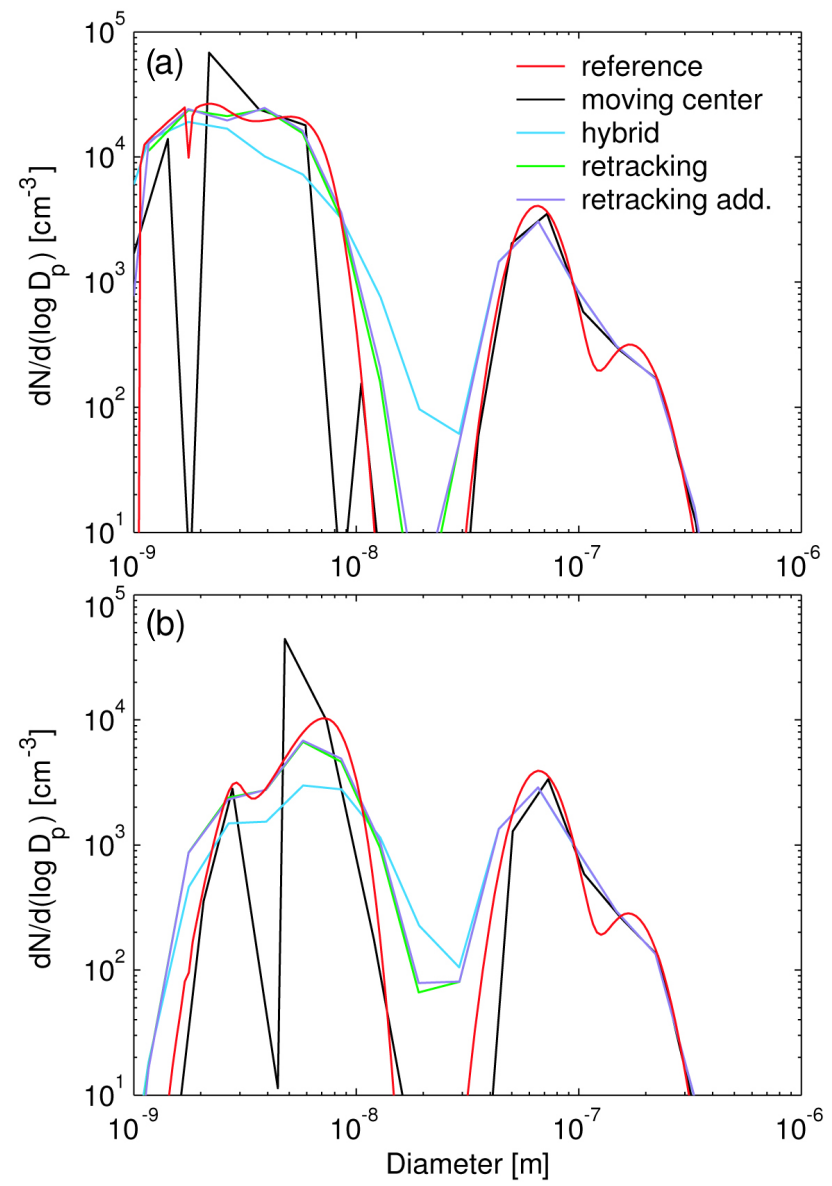

Fig. 2. Size distribution after (a) $5 \mathrm{~h}$ and (b) $10 \mathrm{~h}$ of simulation as predicted by the different size distribution descriptions in the test case. The purple line, labeled "retracking add", refers to the retracking method in which new size section was created for nucleated particles after every ten minutes.

ing method shows noticeably less numerical diffusion than the hybrid structure. As the simulation proceeds, however, the difference becomes less obvious, although the retracking method still represents the nucleation mode distribution more accurately. Moreover, the two simulations with the retracking method give nearly identical size distributions; thus, increasing the computational burden of the code by creating additional sections seems not to improve the model performance. Although the moving center approach eliminates nearly all numerical diffusion, it overestimates the growth of Aitken mode particles and fails to predict the shape of the nucleation mode. The dents in the distribution in the size range of the smallest particles arise from the behaviour of the size distribution structure upon condensation growth. Since all the particles reaching the lower or the upper boundary of the section are moved to the adjacent section, the method frequently produces nearly empty size sections whose only particles result from coagulation. Furthermore, increasing the 

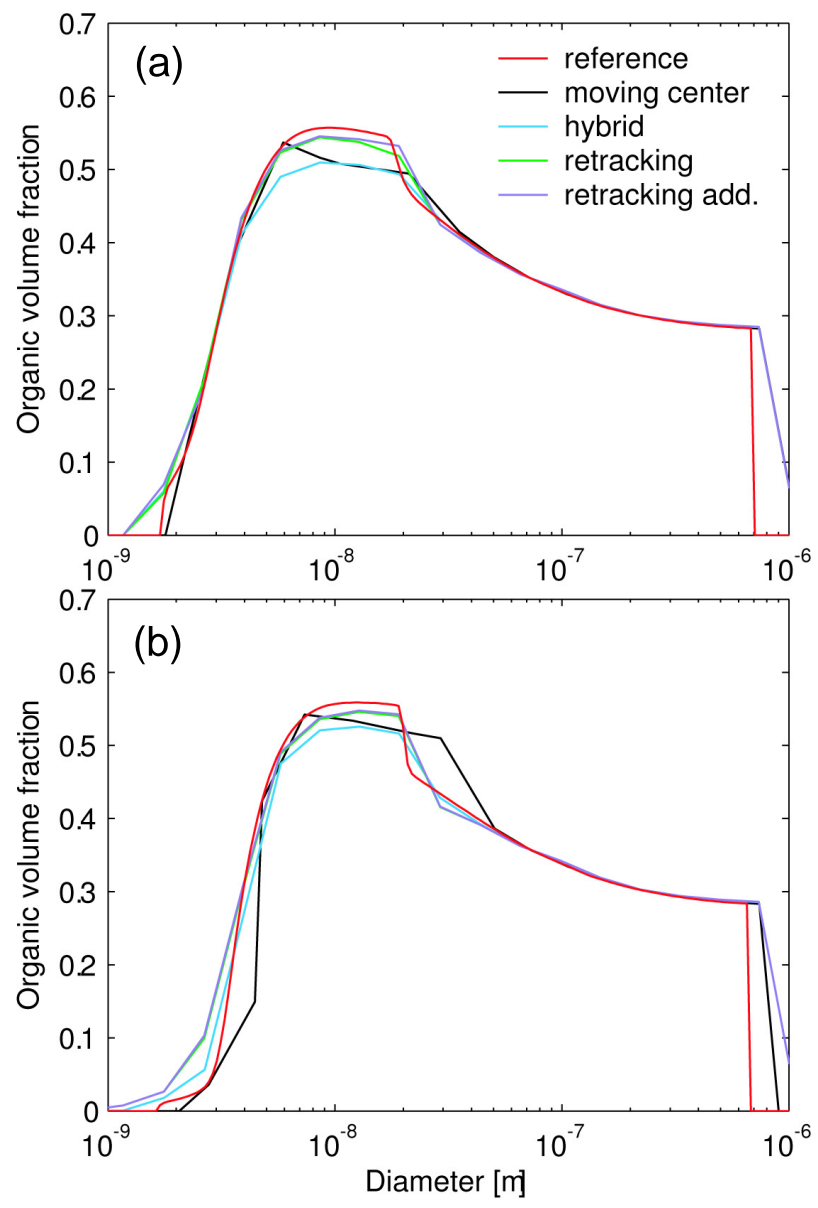

Fig. 3. Organic volume fraction after (a) $5 \mathrm{~h}$ and (b) $10 \mathrm{~h}$ of simulation as predicted by the different size distribution descriptions in the test case. Zero volume ratio indicates either that the size section in question is empty, or the particles do not contain any organic matter.

number of size sections in this method does not smooth the distribution out; in contrast, the particles jump from one section to another more often resulting in even more dents in the plotted distribution. One can also notice that reference results in Fig. 2 show a small dent in the distribution at a size just below $2 \mathrm{~nm}$. At this critical size, as predicted by Nano-Köhler theory, organic vapour starts fast condensation onto newly formed particles. The lower resolution simulations fail to capture this feature of the distribution altogether.

When logarithmic spacing for size sections is used, the problems associated with numerical diffusion and additional dents in the size distribution are most pronounced for the nucleation mode particles. A denser size grid in this region would eliminate numerical diffusion to some extent but at the same time increase the computational burden of the code; as explained above, a denser grid would not, however, smooth out the particle distribution when the moving center approach is used. Another solution to the problems encountered in the nucleation regime could be an accurate parameterization which takes into account not only nucleation but also the early stages of particle growth and thus essentially predicts the appearance rate of particles at a larger size (e.g. at $5 \mathrm{~nm}$ ). In addition, such a parameterization would reduce the number of size sections needed to describe the smallest particles and could therefore decrease the computational cost of the code.

All the size distribution description methods predict very similar particle composition (Fig. 3), and most of the differences spring from the inaccuracies in the particle size distribution predictions. After $5 \mathrm{~h}$, when sulphuric acid and the organic vapour are both still condensing onto the particles, the retracking method captures the particle composition most accurately. Towards the end of the simulation, as the ambient concentrations of condensable vapours falls, the organic vapour starts slowly evaporating from the particles. The retracking method then fails to account for the loss of organic material in the very smallest particle sizes although its prediction of larger than $5 \mathrm{~nm}$ particle composition is still good. In contrast, the moving center method predicts slightly too low organic volume fraction for the nucleation mode particles. On the other hand, comparison with the size distribution (Fig. 2) reveals that the composition prediction with this method shows generally most inaccuracy in size sections which contain negligible particle concentration.

\subsection{Simulation of an observed nucleation event}

In order to test the potential of the model to describe real atmospheric phenomena, we simulated a new particle formation event observed on 19 May 1999 in Hyytiälä, southern Finland. At this site, the particle size distribution and basic meteorological data are monitored continuously; unfortunately, information on the gas-phase concentrations of condensable vapours is not available. The vapour concentrations used in the simulation represent, therefore, typical values measured or estimated at similar locations. The inorganic vapours, apart from water, followed a semisinusoidal pattern with a peak value of $5 \cdot 10^{6} \mathrm{~cm}^{-3}$ for sulphuric acid (Eisele and Tanner, 1993; Weber et al., 1997) and 4 ppt for ammonia. In addition to vapours used in the comparison of size distribution representations above, we included a second low volatile organic vapour whose saturation vapour concentration was $2 \cdot 10^{6} \mathrm{~cm}^{-3}$. Since the organic vapours responsible for the growth of newly formed particles in the atmosphere have not been identified, their formation mechanism is not known. In this study, we have assumed that the condensable organic compounds have followed a semisinusoidal pattern with peak values $2 \cdot 10^{7} \mathrm{~cm}^{-3}$ for the lower volatile and $5 \cdot 10^{6} \mathrm{~cm}^{-3}$ for the higher volatile organic compound. These peak values were obtained by optimizing the model results to reproduce the observed nucleation mode growth rate, and are in agreement with the values found in literature (Kulmala et al., 2001). The observed pre-existing particle 

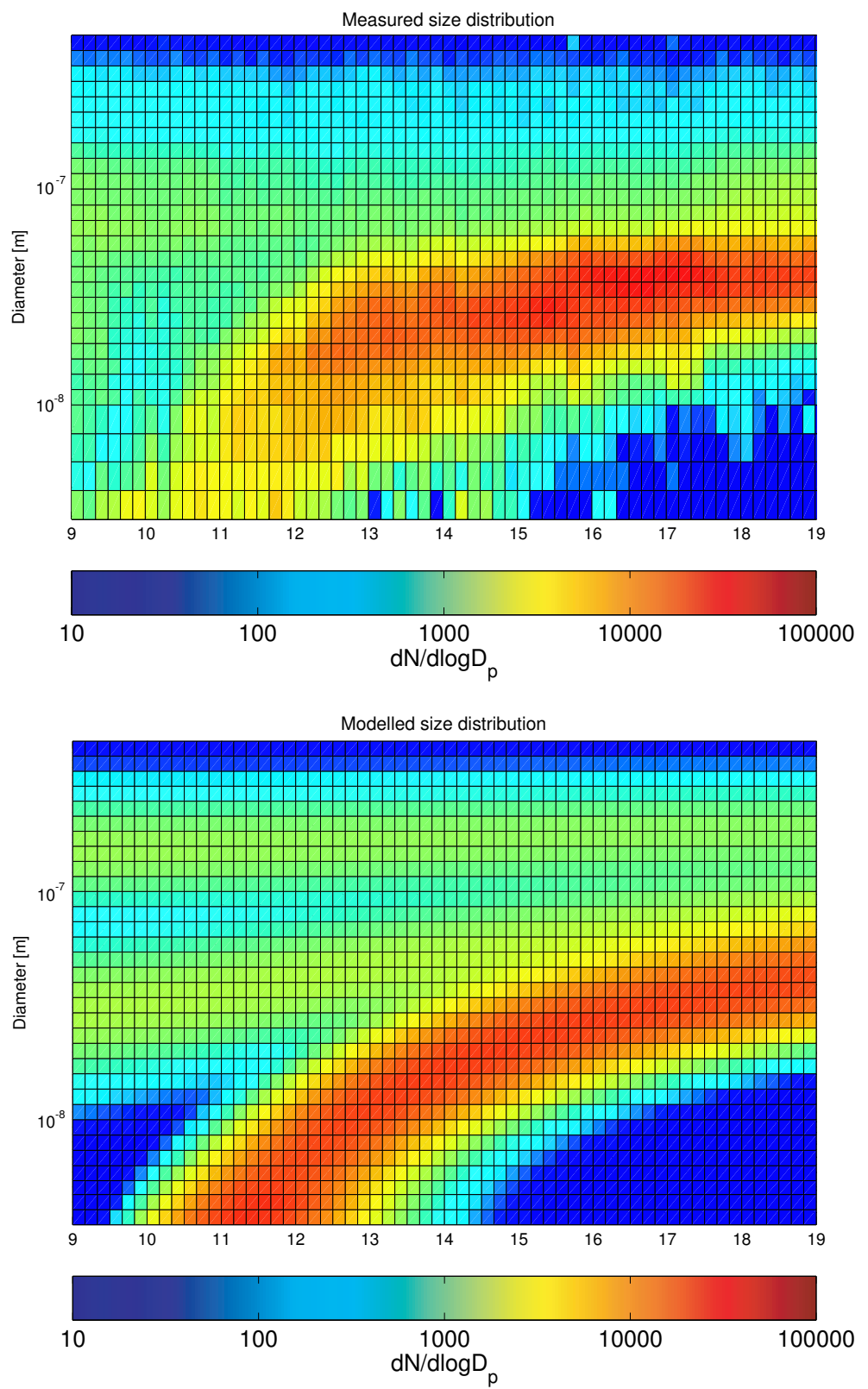

Fig. 4. Measured versus modelled particle size distribution on 19 May 1999 in Hyytiälä, a boreal forest site in southern Finland (second test case). The contour plot displays the particle concentration in $\# / \mathrm{cm}^{3}$ as a function of time and particle size. Due to the lower detection limit of the DMPS measurement system, only particles larger than $3 \mathrm{~nm}$ in diameter are shown.

concentration of approximately $1200 \mathrm{~cm}^{-3}$ was represented with two log-normal modes.

Figure 4 presents the time development of the particle size distribution as measured with a DMPS system and as simulated with 50 size sections in the hybrid structure. The model results obtained using the other two size distribution structures agree with the ones presented here; however, as the moving center structure frequently produces dents and respective peaks in distribution and as the retracking method redistributes the particles into a fixed grid once an hour, the resulting checkerboard plots (such as Fig. 4) are difficult to compare with measurements.

Figure 4 depicts that the model reproduces the qualitative features of the observed nucleation mode evolution well. Lehtinen and Kulmala (2003) have pointed out that numerical diffusion, if present in the models, destroys the narrowing effect of the nucleation mode that is often observed in the growth plot. This explains part of the disagreement between the observed and modelled particle growth at sizes below $10 \mathrm{~nm}$. In addition, the observed newly formed particles 

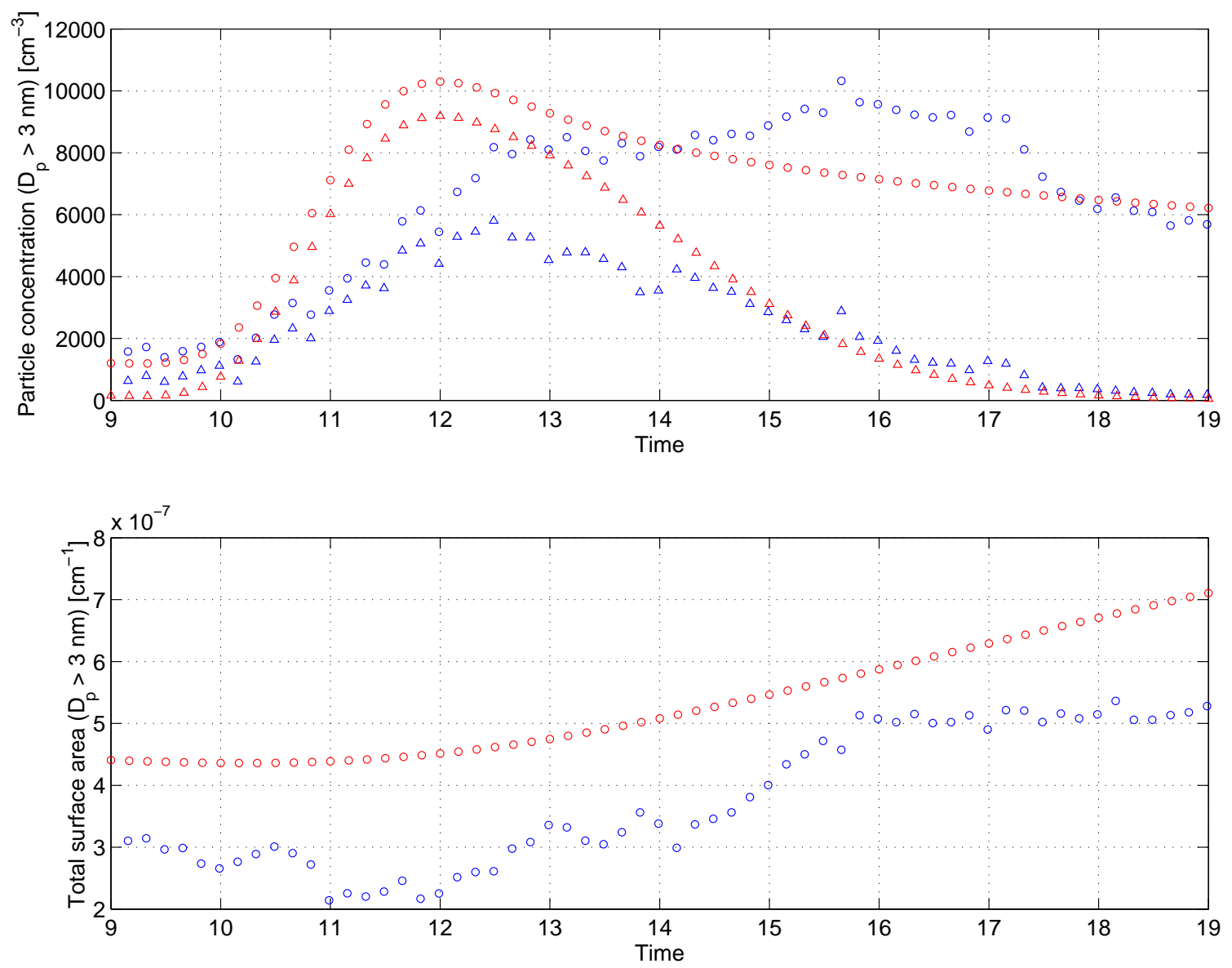

Fig. 5. Comparison of modelled (red) and measured (blue) time evolution of particle number concentration (upper panel) and surface area (lower panel). The modelled results are shown for particles larger than $3 \mathrm{~nm}$ in diameter which is the lower detection limit of the measurement instrument. In the upper panel, the circles correspond to total particle concentration and the triangles to concentration of particles smaller than $20 \mathrm{~nm}$ in diameter.

grow more rapidly than the simulated ones during the first simulation hours and reach the size of $30 \mathrm{~nm}$ in $2.5 \mathrm{~h} \mathrm{com-}$ pared $3.5 \mathrm{~h}$ predicted by the model. This suggests that vapours with lower volatility than simulated may have contributed to the new particle growth in the field. Higher concentrations of sulphuric acid and organic vapours seem unlikely based on the model runs. Unless the uptake of these vapours by pre-existing and newly formed particles is very different due to e.g. their composition, higher concentrations would accelerate also the pre-existing particle growth, and thus lead to increased coagulation sink and supressed new particle formation.

The particle size distribution in Hyytiälä is measured at a fixed location and the measurements are therefore affected by the spatial fluctuations in the air mass. These fluctuations are impossible to capture in a zero-dimensional aerosol model and thus a quantitative comparison of the model results with the measurements is difficult. Figure 5 indicates that the model captures the timing of the new particle formation and the final particle concentration well. It overpredicts, however, the concentration of particles smaller than $20 \mathrm{~nm}$ in diameter during the nucleation burst and underpredicts the total particle concentration between 2 p.m. and 6 p.m. The latter mismatch is clearly due to the air mass properties at the measurement site since new particle formation does not add to the total particle concentration during this period and primary particle emissions are highly unlikely to explain the observed increase. Whereas the air mass properties can account for at least part of the overprediction of the new particle formation rate, another possible explanation lies in the treatment of the vapour concentrations in the model; these are predetermined at the beginning of the simulation and do not, therefore, respond to the increased sink introduced by nucleation and growth of newly formed particles. A more sophisticated treatment of the vapour concentrations would, however, require a gas-phase chemistry model that predicts the vapour production rates and is therefore out of the scope of this paper.

The model captures the time development of the observed total particle surface area well (Fig. 5) considering that the 


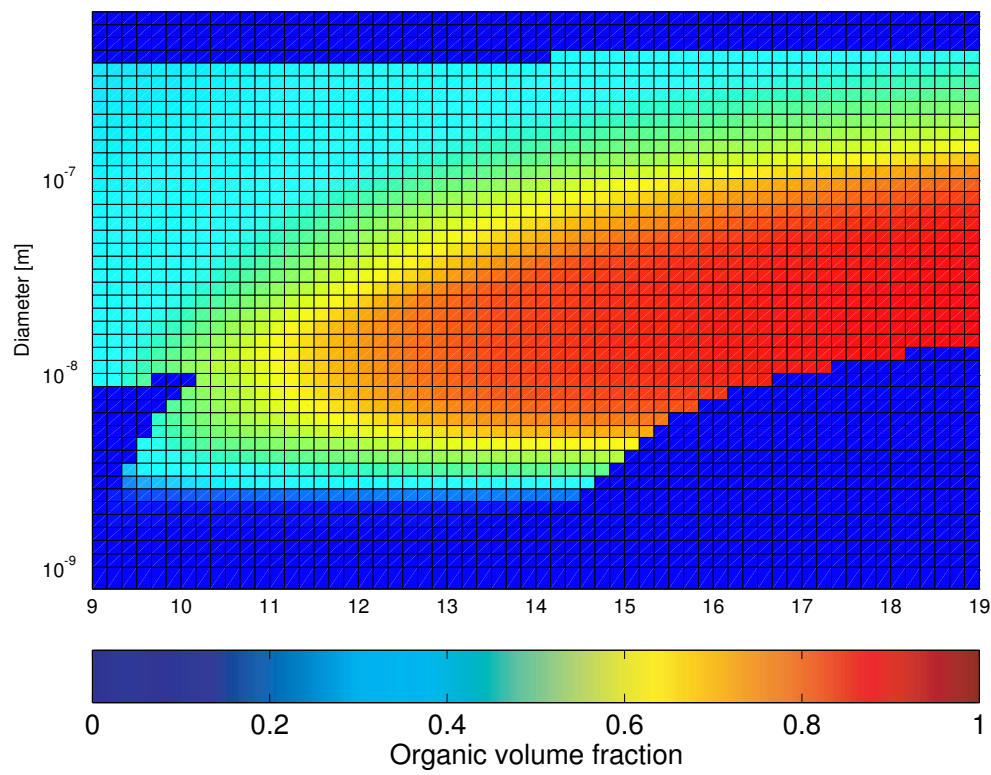

Fig. 6. Model prediction of the organic volume fraction in particles as a function of particle size and simulation time (second test case). Dark blue colour indicates either that the size section in question is empty, or that the particles contain no organic matter.

pre-existing particle population was approximated with two log-normal modes and thus the initial surface area was overestimated by $42 \%$. The largest disagreement with the measurement is observed just before noon when the measured surface area decreases due to some sort of a complex dilution process, observable also in the measured size distribution (Fig. 4), that is very difficult to capture in a model. At the end of the simulation, the overprediction of the surface area is $35 \%$, i.e. close to the error introduced by the choice of the initial pre-existing distribution. A better match of the time development of the total particle number and surface area concentrations could have been obtained by reading in the measured size distribution for Aitken and accumulation mode particles throughout the simulation; this way also the dilution and the fluctuations in the air mass properties could have been accounted for to some extent. As measurement data of this detail is unavailable for most possible model applications, we chose an approximate approach to demonstrate the potential of the model to reproduce the qualitative features of the observed nucleation event.

Figure 6 presents the model prediction of the particle organic volume fraction as a function of particle size and time. The dark blue colour indicates that either no particles exist in the size section or, as is the case with the very smallest particles, the existing particles contain no organic matter. The simulation results suggests that the nucleated particles grow by condensation of sulphuric acid until the size of about $2 \mathrm{~nm}$ after which an organic vapour described by nanoKöhler mechanism begins to condense onto them. Once the particles have reached a diameter of 3-4 nm, half of their volume may consist of organic matter whereas the organic volume fraction in $10 \mathrm{~nm}$ particles may exceed 0.8 . This finding of nucleation mode particles that are predominantly organic in composition supports the indirect measurements reported by O'Dowd et al. (2002). In the atmosphere, the composition of the smallest particles depends, however, strongly on the properties of the condensable vapours, which for the organic species are poorly known.

\section{Conclusions}

In this paper, we have introduced a size-segregated multicomponent aerosol dynamics model UHMA (University of Helsinki Multicomponent Aerosol model), developed for studies of the tropospheric aerosol particles. The code can simulate the size distribution evolution of particles consisting of sulphuric acid, water, and ammonia as well as an unlimited number of water-soluble organic compounds, and water-insoluble compounds such as mineral dust, elemental carbon and organic species. The first model version focuses on the simulation of atmospheric new particle formation and growth, and incorporates novel parameterizations for homogeneous binary nucleation of $\mathrm{H}_{2} \mathrm{SO}_{4}-\mathrm{H}_{2} \mathrm{O}$ mixture, ternary nucleation of $\mathrm{H}_{2} \mathrm{SO}_{4}-\mathrm{NH}_{3}-\mathrm{H}_{2} \mathrm{O}$ mixture, and particle dry deposition. In addition, it accounts for particle loss by coagulation, and for particle growth by multicomponent condensation, applying a recently revised formulation of condensation flux onto the free molecular regime particles as well as the Nano-Köhler theory (Kulmala et al., 2004a).

In UHMA, the representation of the size distribution can be chosen from three sectional approaches: the hybrid method, the moving center method and the retracking method, in which moving size sections are retracked to a 
fixed grid after a desired time interval. A test simulation of a new particle formation event against a highly accurate solution revealed that the hybrid structure requires more size sections than the other two methods to reproduce the number concentration of formed particles accurately. It is also the most vulnerable to numerical diffusion upon particle growth although the retracking method performs only slightly better in this respect. The moving center method, on the other hand, eliminates practically all artificial widening of the distribution; it may even somewhat narrow the distribution artificially. This method also predicts undesired dents in the nucleation mode region of the size distribution and suffers from built-in problems to predict the time required for the particles to grow to detectable, or respectively to $\mathrm{CCN}$, sizes.

On the whole, all of the methods offer a reasonable treatment of nucleation, particle emissions and atmospheric transport while eliminating much of the numerical diffusion inherent to fixed grid methods. Despite their shortcomings, they are therefore highly potential candidates for large scale atmospheric models which require computational efficiency and consistent allocation of particles from one model grid point to another. As the test presented in this study was by no means complete, it is at the present impossible to draw any final conclusions on which of the approaches is the most advantageous for 3-D applications.

A comparison to an observed nucleation event shows that UHMA is capable of predicting the qualitative behaviour of atmospherically relevant phenomena with good accuracy. Furthermore, the model predicts that even if the species forming new particles via nucleation are inorganic, organic compounds may well dominate the composition of nucleation mode particles larger than $3-4 \mathrm{~nm}$ in diameter. This finding is further supported by the recent measurement data of O'Dowd et al. (2002).

Edited by: A. Laaksonen

\section{References}

Ackerman, I. J., Hass, H., Memmesheimer, M., Ebel, A., Binkowski, F. S., and Shankar, U.: Modal aerosol dynamics model for Europe: development and first applications, Atmos. Environ., 32, 2981-2999, 1998.

Adams, P. J. and Seinfeld, J. H.: Predicting global aerosol size distributions in general circulation models, J. Geophys. Res., 107, D19, 4370, doi:10.1029/2001JD001010, 2002.

Adams, P. J., Seinfeld, J. H., Koch, D., Mickley, L., and Jacob, D.: General circulation model assessment of direct radiative forcing by the sulfate-nitrate-ammonium-water inorganic aerosol system, J. Geophys. Res., 107, 1097-1111, 2001.

Atkinson, R. W., Bremner, S. A., Anderson, H. R., Strachan, D. P., Bland, J. M., and Ponce de Leon, A.: Short-term associations between emergency hospital admissions for respiratory and cardiovascular disease and outdoor air pollution in London, Arch. Environ. Health, 54, 398-411, 1999.
Ball, S. M., Hanson, D. R., and Eisele, F. L.: Laboratory studies of particle nucleation: Initial results for $\mathrm{H}_{2} \mathrm{SO}_{4}, \mathrm{H}_{2} \mathrm{O}$, and $\mathrm{NH}_{4}$ vapor, J. Geophys. Res., 104, 23 709-23 718, 1999.

Ball, W. P., Dickerson, R. R., Doddridge, B. G., Stehr, J. W., Miller, T. L., Savie, D. L., and Carsey, T. P.: Bulk and size-segregated aerosol composition observed during INDOEX 1999: Overview of meteorology and continental impacts, J. Geophys. Res., 108, D10, 8001, doi:10.1029/2002JD002467, 2003.

Birmili, W., Wiedensohler, A., Plass-Dülmer, C., and Berresheim, H.: Evolution of newly formed aerosol particles in the continental boundary layer: A case study including $\mathrm{OH}$ and $\mathrm{H}_{2} \mathrm{SO}_{4}$ measurements, Geophys. Res. Lett., 27, 2205-2208, 2000.

Boland, S., Bonvallot, V., Fournier, T., Baeza-Squiban, A., Aubier, M., and Marano, F.: Mechanisms of GM-CSF increase by diesel exhaust particles in human airway epithelial cells, Am. J. Physiol. Lung Cell Mol. Physiol., 278, L25-L32, 2000.

Bonn, B. and Moortgat, G. K.: Sesquiterpene ozonolysis: Origin of atmospheric new particle formation from biogenic hydrocarbons, Geophys. Res. Lett., 30, 11, 1585, doi:10.1029/2003GL017000, 2003.

Boy, M., Rannik, Ü., Lehtinen, K. E. J., Tarvainen, V., Hakola, H., and Kulmala, M.: Nucleation events in the continental PBL Long term statistical analysis of aerosol relevant characteristics, J. Geophys. Res., 108, D21, 4667, doi:10.1029/2003JD003838, 2003.

Brown, D. M., Wilson, M. R., MacNee, W., Stone, V., and Donaldson, K.: Size-dependent proinflammatory effects of ultrafine polystyrene particles: A role for surface area and oxidative stress in the enhanced activity of ultrafines, Toxicol. Appl. Pharmocol., 175, 191-199, 2001.

Charlson, R. J., Schwartz, S. E., Hales, J. M., Cess, R. D., Coakley Jr., J. A., Hansen, J. E., and Hofmann, D. J.: Climate forcing by anthropogenic aerosols, Science, 255, 423-430, 1992.

Choi, M. Y. and Chan, C. K.: The effects of organic species on the hygroscopic behaviors of inorganic aerosols, Environ. Sci. Technol., 36, 2422-2428, 2002.

Chung, S. H. and Seinfeld, J. H.: Global distribution and climate forcing of carbonaceous aerosols, J. Geophys. Res., 107, D19, 4407, doi:10.1029/2001JD001397, 2002.

Claquin, T., Schulz, M., Balkanski, Y., and Boucher, O.: Uncertainties in assessing the radiative forcing by mineral dust, Tellus, 50B, 491-505, 1998.

Clarke, A. D., Davis, D., Kapustin, V. N., Eisele, F., Chen, G., Paluch, I., Lenschow, D., Bandy, A. R., Thornton, D., Moore, K., Mauldin, L., Tanner, D., Litchy, M., Carroll, M. A., Collings, J., and Albercook, G.: Particle nucleation in the tropical boundary layer and its coupling to marine sulfur sources, Science, 282, 89-91, 1998.

Clegg, S. L., Brimblecombe, P., and Wexler, A. S.: A thermodynamic model of the system $\mathrm{H}-\mathrm{NH}_{4}-\mathrm{SO}_{4}-\mathrm{NO}_{3}-\mathrm{H}_{2} \mathrm{O}$ at tropospheric temperatures, J. Phys. Chem. A, 102, 2137-2152, 1998.

Clement, C. F., Kulmala, M., and Vesala, T.: Theoretical considerations on sticking probability, J. Aerosol Sci., 27, 869-882, 1996.

Coffman, D. J. and Hegg, D. A.: A preliminary study of the effect of ammonia on particle nucleation in the marine boundary layer, J. Geophys. Res., 100, 7147-7160, 1995.

Covert, D. S., Kapustin, V. N., Bates, T. S., and Quinn, P. K.: New particle formation in the marine boundary layer, J. Geophys. Res., 97, 20 581-20 589, 1992. 
Cruz, C. N. and Pandis, S. N.: Deliquescence and hygroscopic growth of mixed inorganic-organic atmospheric aerosol, Environ. Sci. Technol., 34, 4313-4319, 2000.

Dhaniyala, S. and Wexler, A.: Numerical schemes to model condensation and evaporation of aerosols, Atmos. Environ., 30, 919928, 1996.

Dockery, D. W., Pope, C. A., Xu, X., Spengler, J. D., Ware, J. H., Fay, M. E., Ferris, B. G., and Speizer, F. E.: An association between air pollution and mortality in six US cities, N. Engl. J. Med., 329, 1753-1759, 1993.

Doyle, G. J.: Self nucleation in the sulfuric acid-water system, J. Chem. Phys., 35, 795-799, 1961.

Eisele, F. and Tanner, D.: Measurement of the gas phase concentration of $\mathrm{H}_{2} \mathrm{SO}_{4}$ and methane sulfonic acid and estimates of $\mathrm{H}_{2} \mathrm{SO}_{4}$ production and loss in the atmosphere, J. Geophys. Res., 98, 9001-9010, 1993.

Feingold, G., Cotton, W. R., Kreidenweis, S. M., and Davis, J. T.: Impact of giant cloud condensation nuclei on drizzle formation in marine stratocumulus: Implications for cloud radiative properties, J. Aerosol Sci., 56, 4100-4117, 1999.

Fitzgerald, J. W., Marti, J. J., Hoppel, W. A., Frick, G. M., and Gelbard, F.: A one-dimensional sectional model to simulate multicomponent aerosol dynamics in the marine boundary layer, 2 . Model application, J. Geophys. Res., 103, 16 103-16 117, 1998.

Fuchs, N. A.: The mechanics of aerosols, Dover, New York, 1964.

Fuchs, N. A. and Sutugin, A. G.: Highly dispersed aerosol, in Topics in current aerosol research, edited by Hidy, G. M. and Brock, J. R., Pergamon, New York, 1971.

Ghan, S. J., Easter, R. C., Chapman, E. G., Abdul-Razzak, H., Zhang, Y., Leung, L. R., Laulainen, N. S., Saylor, R. D., and Zaveri, R. A.: A physically based estimate of radiative forcing by anthropogenic sulfate aerosol, J. Geophys. Res., 106, 52795293, 2001a.

Ghan, S., Laulainen, N., Easter, R., Wagener, R., Nemesure, S., Chapman, E., Zhang, Y., and Leung, R.: Evaluation of aerosol direct radiative forcing in MIRAGE, J. Geophys, Res., 106, 52955316, 2001b.

Giebl, H., Berner, A., Reischl, G., Puxbaum, H., Kasper-Giebl, A., and Hitzenberger, R.: CCN activation of oxalic and malonic acid test aerosols with the University of Vienna cloud condensation nuclei counter, J. Aerosol Sci., 33, 1623-1634, 2002.

Goldsmith, C.-A. W., Imrich, A., Danaee, H., Ning, Y. Y., and Kobzik, L.: Analysis of air pollution particulate-mediated oxidant stress in alveolar macrophages, J. Toxicol. Environ. Health A, 54, 529-545, 1998.

Gong, S. L., Zhang, X. Y., Zhao, T. L., McKendry, I. G., Jaffe, D. A., and Lu, N. M.: Characterization of soil dust aerosol in China and its transport and distribution during 2001 ACE-Asia: 2. Model simulation and validation, J. Geophys, Res., 108, D9, 4262, doi:10.1029/2002JD002633, 2003.

Gordian, M. E. and Choudhury, A. H.: PM $_{10}$ and asthma medication in school children, Arch. Environ. Health, 58, 42-47, 2003.

Griffin, R. J., Dabdub, D., Kleeman, M. J., Fraser, M. P., Cass, G. R., and Seinfeld, J. H.: Secondary organic aerosol, 3. Urban/regional scale model of size- and composition-resolved aerosols, J. Geophys. Res., 107, D17, 4334, doi:10.1029/2001JD000544, 2002.

Guimbaud, C., Arens, F., Gutzwiller, L., Gaggeler, H. W., and Ammann, M.: Uptake of $\mathrm{HNO}_{3}$ to deliquescent sea-salt particles: a study using the short-lived radioactive isotope tracer $13 \mathrm{~N}$, Atmos. Chem. Phys., 2, 249-257, 2002.

Hanson, D. and Kosciuch, E.: The $\mathrm{NH}_{3}$ mass accommodation coefficient for uptake onto sulfuric acid solutions, J. Phys. Chem. A, 107, 2199-2208, 2003.

Hiura, T. S., Kaszubowski, M. P., Li, N., and Nel, A. E.: Chemicals in diesel exhaust particles generate reactive oxygen radicals and induce apoptosis in macrophages, J. Immunol., 163, 5582-5591, 1999.

Intergovernmental Panel on Climate Change (IPCC): Climate Change 2001: The scientific basis, Contribution of working group I to the third assessment report of the intergovernmental panel on climate change, edited by Houghton, J. T., Ding, Y., Griggs, D. J., et al., Cambridge University Press, New York, 881, 2001.

Ishizaka, Y. and Adhikari, M.: Composition of cloud condensation nuclei, J. Geophys. Res., 108, 4138, doi:10.1029/2002JD002085, 2003.

Jacobson, M. Z.: Development and application of a new air pollution modeling system - II. Aerosol module structure and design, Atmos. Environ., 31, 131-144, 1997.

Jacobson, M. Z.: Strong radiative heating due to the mixing state of black carbon in atmospheric aerosols, Nature, 409, 695-697, 2001.

Jacobson, M. Z.: Analysis of aerosol interactions with numerical techniques for solving coagulation, nucleation, condensation, dissolution, and reversible chemistry among multiple size distributions, J. Geophys. Res., 107, D19, 4366, doi:10.1029/2001JD002044, 2002.

Jacobson, M. Z. and Turco, R. P.: Simulating condensational growth, evaporation, and coagulation of aerosols using a combined moving and stationary size grid, Aerosol Sci. Technol., 22 , 73-92, 1995.

Jimenez, J. L., Jayne, J. T., Shi, Q., Kolb, C. E., Worsnop, D. R., Yourshaw, I., Seinfeld, J. H., Flagan, R. C., Zhang, X., Smith, K. A., Morris, J. W., and Davidovits, P.: Ambient aerosol sampling using the Aerodyne Aerosol Mass Spectrometer, J. Geophys. Res., 108, D7, 8425, doi:10.1029/2001JD001213, 2003.

Jones, A., Roberts, D. L., and Slingo, A.: A climate model study of indirect radiative forcing by anthropogenic sulfate aerosols, Nature, 370, 450-453, 1994.

Kanakidou, M., Tsigaridis, K., Dentener, F. J., and Crutzen, P. J.: Human-activity-enchanced formation of organic aerosols by biogenic hydrocarbon oxidation, J. Geophys. Res., 105, 9243-9254, 2000.

Kim, T. O., Ishida, T., Adachi, M., Okuyama, K., and Seinfeld, J. H.: Nanometer-sized particle formation from $\mathrm{NH}_{3} / \mathrm{SO}_{2} / \mathrm{H}_{2} \mathrm{O} /$ air mixtures by ionizing irradiation, Aerosol Sci. Technol., 29, 111125,1998

Koo, B., Ansari, A. S., and Pandis, S. P.: Integrated approaches to modeling the organic and inorganic atmospheric aerosol components, Atmos. Environ., 37, 4757-4768, 2003.

Korhonen, H., Lehtinen, K. E. J., Pirjola, L., Napari, I., Vehkamäki, H., Noppel, M., and Kulmala M.: Simulation of atmospheric nucleation mode: A comparison of nucleation models and size distribution descriptions, J. Geophys. Res., 108, D15, 4471, doi:10.1029/2002JD003305, 2003.

Korhonen, P., Kulmala, M., Laaksonen, A., Viisanen, Y., McGraw, R., and Seinfeld, J. H.: Ternary nucleation of $\mathrm{H}_{2} \mathrm{SO}_{4}, \mathrm{NH}_{3}$ and 
$\mathrm{H}_{2} \mathrm{O}$ in the atmosphere, J. Geophys. Res., 104, 26349-26353, 1999.

Künzli, N., Kaiser, R., Medina, S., Studnicka, M., Chanel, O., Filliger, P., Herry, M., Horak Jr., F., Puybonnieux-Texier, V., Quénel, P., Schneider, J., Seethaler, R., Vergnaud, J.-C., and Sommer, H.: Public-health impact of outdoor and traffic-related air pollution: a European assessment, Lancet, 356, 795-801, 2000.

Kulmala, M.: How particles nucleate and grow, Science, 302, 10001001, 2003.

Kulmala, M., Laaksonen, A., and Pirjola, L.: Parametrizations for sulfuric acid/water nucleation rates, J. Geophys. Res., 103, 83018308, 1998.

Kulmala, M., Dal Maso, M., Mäkelä, J. M., Pirjola, L., Väkevä, M., Aalto, P., Miikkulainen, P., Hämeri, K., and O'Dowd, C. D.: On the formation, growth and composition of nucleation mode particles, Tellus, 53B, 479-490, 2001.

Kulmala, M., Kerminen, V.-M., Anttila, T., Laaksonen, A., and O'Dowd, C. D.: Organic aerosol formation via sulphate cluster activation, J. Geophys. Res., 109, (D4), 4205, doi:10.1029/2003JD003961, 2004a.

Kulmala, M., Vehkamäki, H., Petäjä, T., Dal Maso, M., Lauri, A., Kerminen, V.-M., Birmili, W., and McMurry, P. H.: Formation and growth rates of ultrafine atmospheric particles: A review of observations, J. Aerosol Sci., 35, 143-176, 2004b.

Laaksonen, A. and Oxtoby, D. W.: Gas-liquid nucleation of nonideal binary mixtures, 1 . A density functional study, J. Chem. Phy., 102, 5803-5810, 1995.

Lake, D. A., Tolocka, M. P., Johnston, M. V., and Wexler, A. S.: Mass spectrometry of individual particles between 50 and $750 \mathrm{~nm}$ in diamter at the Baltimore supersite, Environ. Sci. Technol., 37, 3268-3274, 2003.

Lambert, A. L., Dong, W., Selgrade, M. J. K., and Gilmour, M. I.: Enhanced allergic sensitization by residual oil fly ash particles is mediated by soluble metal constituents, Toxicol. Appl. Pharmacol., 165, 84-93, 2000.

Lehtinen, K. E. J. and Kulmala, M.: A model for particle formation and growth in the atmosphere with molecular resolution in size, Atmos. Chem. Phys., 2, 251-257, 2003.

Levin, Z., Gaynor, E., and Gladstein, V.: The effects of desert particles coated with sulfate on rain formation in the Eastern Mediterrean, J. Appl. Meterol., 35, 1511-1523, 1996.

Liao, H. and Seinfeld, J. H.: Radiative forcing by mineral dust aerosols: Sensitivity to key variables, J. Geophys. Res., 101, 19237-19244, 1998.

Lurmann, F. W., Wexler, A. S., Pandis, S. N., Musarra, S., Kumar, N., and Seinfeld, J. H.: Modelling urban and regional aerosols - II. Application to California's south coast air basin, Atmos. Environ., 17, 2695-2715, 1997.

Mäkelä, J. M., Aalto, P., Jokinen, V., Pohja, T., Nissinen, A., Palmroth, S., Markkanen, T., Seitsonen, K., Lihavainen, H., and Kulmala, M.: Observations of ultrafine aerosol particle formation and growth in boreal forest, Geophys. Res. Lett., 24, 1219-1222, 1997.

Mäkelä, J., Koponen, I. K., Aalto, P., and Kulmala, M.: Oneyear data of submicron size modes of tropospheric background aerosol in Southern Finland, J. Aerosol Sci., 31, 595-611, 2000.

Marti, J., Jefferson, A., Cai, X. P., Richert, C., McMurry, P., and Eisele, $\mathrm{F}$.: $\mathrm{H}_{2} \mathrm{SO}_{4}$ vapor pressure of sulfuric acid and ammonium sulfate solutions, J. Geophys. Res., 102, 3725-3735, 1997.

Matsumoto, K., Tanaka, H., Nagao, I., and Ishizaka, Y.: Contribution of particulate sulfate and organic carbon to cloud condensation nuclei in the marine atmosphere, Geophys. Res. Lett., 24, 655-658, 1997.

Maynard, A. D. and Maynard, R. L.: A derived association between ambient aerosol surface area and excess mortality using historic time series data, Atmos. Environ., 36, 5561-5567, 2002.

Meng, Z., Dabdub, D., and Seinfeld, J. H.: Size-resolved and chemically resolved model of atmospheric aerosol dynamics, J. Geophys. Res., 103, 3419-3435, 1998.

Morita, A.: Molecular dynamics study of mass accommodation of methanol at liquid-vapor interfaces of methanol/water binary solutions of water concentrations, Chem. Phys. Lett., 375, 1-8, 2003.

Murphy, D. M., Anderson, J. R., Quinn, P. K., McInnes, L. M., Brechtel, F. J., Kreidenweis, S. M., Middlebrook, A. M., Posfai, M., Thomson, D. S., and Buseck, P. R.: Influence of sea-salt on aerosol radiative properties in the Southern Ocean marine boundary layer, Nature, 392, 62-65, 1998

Napari, I. and Laaksonen, A.: Surfactant Effects and an OrderDisorder Transition in Binary Gas-Liquid Nucleation, Phys. Rev. Lett., 84, 2184-2187, 2000.

Napari, I., Noppel, M., Vehkamäki, H., and Kulmala, M.: An improved model for ternary nucleation of sulfuric-acid-ammonia water, J. Chem. Phys., 116, 4221-4227, 2002a.

Napari, I., Noppel, M., Vehkamäki, H., and Kulmala, M.: Parameterization of ternary nucleation rates for $\mathrm{H}_{2} \mathrm{SO}_{4}$ $\mathrm{NH}_{3}-\mathrm{H}_{2} \mathrm{O}$ vapors, J. Geophys. Res., 107, D19, 4381, doi:10.1029/2002JD002132, 2002b.

Noppel, M., Vehkamäki, H., and Kulmala, M.: An improved model for hydrate formation in sulfuric-acid water nucleation, J. Chem. Phys., 116, 218-228, 2002.

Nguyen, K. and Dabdub, D.: Semi-Lagrangian flux scheme for the solution of the aerosol condensation/evaporation equation, Aerosol Sci. Technol., 36, 407-418, 2002.

Obot, C. J., Morandi, M. T., Beebe, T. P., Hamilton, R. F., and Holian, A.: Surface components of airborne particulate matter induce macrophage apoptosis through scavenger reveptors, Toxicol. Appl. Pharmocol., 184, 98-106, 2002.

O’Dowd, C. D., Becker, E., Mäkelä, J. M., and Kulmala, M.: Aerosol physico-chemical characteristics over a boreal forest determined by volatility analysis, Boreal Env. Res., 5, 337-348, 2000.

O’Dowd, C. D., Aalto, P., Hämeri, K., Kulmala, M., and Hoffmann, T.: Atmospheric particles from organic vapours, Nature, 416, 497-498, 2002.

Pilinis, C., Seinfeld, J. H., and Seigneur, C.: Mathematical modeling of the dynamics of multicomponent atmospheric aerosols, Atmos. Environ., 21, 943-955, 1987.

Pirjola, L. and Kulmala, M.: Development of particle size and composition distribution with aerosol dynamics model AEROFOR2, J. Aerosol Sci., 31, 936-937, 2000a.

Pirjola, L. and Kulmala, M.: Aerosol dynamical model MULTIMONO, Boreal Environ. Res., 5, 361-274, 2000 b.

Pirjola, L., Laaksonen, A., Aalto, P., and Kulmala, M.: Sulphate aerosol formation in the Arctic boundary layer, J. Geophys. Res. 103, 8309-8322, 1998.

Pirjola, L., Kulmala, M., Wilck, M., Bischoff, A., Stratmann, F., 
and Otto, E.: Effects of aerosol dynamics on the formation of sulphuric acid aerosols and cloud condensation nuclei, J. Aerosol Sci., 30, 1079-1094, 1999.

Pirjola, L., Tsyro, S., Tarrason, L., and Kulmala, M.: A monodisperse aerosol dynamics module - a promising candidate for use in the Eulerian long-range transport model: Box model tests, J. Geophys. Res., 108, D9, 4258, doi:10.1029/2002JD002867, 2003.

Pöschl, U., Canagaratna, M., Jayne, J. T., Molina, L. T., Worsnop, D. R., Kolb, C. E., and Molina, M. J.: Mass accomodation coefficient of $\mathrm{H}_{2} \mathrm{SO}_{4}$ vapor on aqueous sulfuric acid surfaces and gaseous diffusion coefficient of $\mathrm{H}_{2} \mathrm{SO}_{4}$ in $\mathrm{N}_{2} / \mathrm{H}_{2} \mathrm{O}$, J. Phys. Chem., 102, 10 082-10 089, 1998.

Putaud, J. P., Van Dingenen, R., and Raes, F.: Submicron aerosol mass balance at urban and semirural sites in the Milan area (Italy), J. Geophys. Res., 107, D22, 8198, doi:10.1029/2000JD000111, 2002.

Raes, F. and Van Dingenen, R.: Simulations of condensation and cloud condensation nuclei from biogenic $\mathrm{SO}_{2}$ in the remote marine boundary layer, J. Geophys. Res., 97, 12 901-12 912, 1992.

Rannik, Ü., Aalto, P., Keronen, P., Vesala, T., and Kulmala, M.: Interpretation of aerosol particle fluxes over a pine forest: Dry deposition and random errors, J. Geophys. Res., 108, D17, 4544, doi:10.1029/2003JD003542, 2003.

Reid, R. C., Prausnitz, J. M., and Poling, B. E.: The properties of gases and liquids, 4th edn., McGraw-Hill, New York, 1987.

Seaton, A., MacNee, W., Donaldson, K., and Godden, D.: Particulate air polution and acute health effects, Lancet, 345, 176-178, 1995.

Seinfeld, J. H. and Pandis, S. N.: Atmospheric Chemistry and Physics: From Air Pollution to Climate Change, John Wiley, New York, 1998.

Sokolik, I. and Toon, O. B.: Dust radiative forcing by anthropogenic airborne mineral aerosols, Nature, 381, 681-683, 1996.

Sokolik, I. N., Winker, D. M., Bergametti, G., Gillette, D. A., Carmichael, G., Kaufman, Y. J., Gomes, L., Schuetz, L., and Penner, J. E.: Introduction to special section: Outstanding problems in quantifying the radiative impacts of mineral dust, J. Geophys. Res., 106, 18 015-18 027, 2001.

Stokes, R. H. and Robinson, R. A.: Interactions in aqueous nonelectrolyte solutions, I Solute-solvent equilibria, J. Phys. Chem., 70, 2126-2130, 1966.

Svenningson, I., Hansson, H.-C., Wiedensohler, A., Orgen, J. A., and Nonne, K. J.: Hygroscopic growth of aerosol particles in the Po Valley, Tellus, 44B, 556-569, 1992.

Van Dingenen, R. and Raes, F.: Determination of the condensation accomodation coefficient of sulfuric acid on water-sulfuric acid aerosol, Aerosol Sci. Technol., 15, 93-106, 1991.
Vehkamäki, H. and Ford, I. J.: Critical cluster size and droplet nucleation rate from growth and decay simulations of LennerdJones clusters, J. Chem. Phys., 112, 4193-4202, 2000.

Vehkamäki, H., Kulmala, M., Napari, I., Lehtinen, K. E. J., Timmreck, C., Noppel, M., and Laaksonen, A.: An improved parameterization for sulfuric acid/water nucleation rates for tropospheric and stratospheric conditions, J. Geophys. Res., 107, D22, 4622, doi:10.1029/2002JD002184, 2002.

Viisanen, Y., Kulmala, M., and Laaksonen, A.: Experiments on gasliquid nucleation of sulfuric acid and water, J. Chem. Phys., 107, 920-926, 1997.

Virkkula, A., Van Dingenen, R., Raes, F., and Hjorth, J.: Hygroscopic properties of aerosol formed by oxidation of limonen, $\alpha$ pinene, and $\beta$-pinene, J. Geophys. Res., 104, 3569-3579, 1999.

Weber, R. J., Marti, J. J., and McMurry, P. H.: Growth rates of ultrafine particles at remote marine and continental sites, AAAR'95, Abstracts of the 14th Annual General Meeting, Pittsburgh, Pennsylvania, USA, 157, 1995.

Weber, R. J., Marti, J. J., McMurry, P. H., Eisele, F. L., Tanner, D. J., and Jefferson, A.: Measurements of new particle formation and ultrafine particle growth rates at a clean continental site, J. Geophys. Res., 102, 4375-4385, 1997.

Weber, R. J., McMurry, P. H., Mauldin, R. L., Tanner, D., Eisele, F. L., Clarke, A. D., and Kapustin, V.: New particle formation in the remote troposphere: A comparison of observations at various sites, Geophys. Res. Lett., 26, 307-310, 1999.

Wilson, J., Cuvelier, C., and Raes, F.: A modeling study of global mixed aerosol fields, J. Geophys. Res., 106, 34081-34 108, 2001.

Worsnop, D. R., Shi, Q., Jayne, J. T., Kolb, C. E., Swartz, E., and Davidovits, P.: Gas-phase diffusion in droplet train measurements of uptake coefficients, J. Aerosol Sci., 32, 877-891, 2001.

Wyzga, R. E. and Folinsbee, L. J.: Health effects of acid aerosols, Water, Air, and Soil Pollut., 85, 177-188, 1995.

Yu, F. and Turco, R. P.: Ultrafine aerosol formation via ionmediated nucleation, Geophys. Res. Lett., 27, 883-886, 2000.

Zappoli, S., Andracchio, A., Fuzzi, S., Facchini, M. C., Gelencser, A., Kiss, G., Krivacsy, Z., Molnar, A., Meszaros, E., Hansson, H.-C., Rosman, K., and Zebuhr, Y.: Inorganic, organic and macromolecular components of fine aerosol in different areas of Europe in relation to their water solubility, Atmos. Environ., 33, 2733-2743, 1999.

Zeleznik, F. J.: Thermodynamic properties of the aqueous sulfuric acid system to 350 K, J. Phys. Chem. Ref. Data, 20, 1157-1200, 1991.

Zhang, X. Q., McMurry, P. H., Hering, S. V., and Casuccio, G. S.: Mixing characteristics and water content of submicron aerosols measured in Los Angeles and at the Grand Canyon, Atmos. Environ., 27A, 1593-1607, 1993. 